\title{
'This is (not) Entertainment!': media constructions of political scandal \\ discourses in the 2016 US presidential election
}

Media, Culture \& Society 2019, Vol. 41 (4) 4I7-432

(C) The Author(s) 2019

Article reuse guidelines: sagepub.com/journals-permissions DOI: 10.1 I77/0I634437/9833288 journals.sagepub.com/home/mcs

@SAGE

\section{Laura Vorberg}

Friedrich-Alexander-Universitat Erlangen-Nurnberg, Germany

\section{Anna Zeitler}

Friedrich-Alexander-Universitat Erlangen-Nurnberg, Germany

\begin{abstract}
The phenomenon of scandal(ization) has become omnipresent in contemporary political media discourses - at the latest since the 2016 US presidential election. Our article addresses causes and effects of this recent prevalence of scandal narratives. By connecting concepts from social systems theory and media theory, we consider crucial practices and processes of scandal construction in the 2016 US presidential election, focusing on the much-noticed emailgate and trumptape scandals. Both examples serve to illustrate how the emergence of partial public spheres in social media may lead to a fight for sovereignty over scandal discourse, political attitudes, and the negotiation of social norms, morals, and values.
\end{abstract}

\section{Keywords}

2016 US presidential election, Clinton, mass media, media events, media scandal, political scandal, scandal, social media, Trump

\section{Introduction}

Since the US presidential inauguration of Donald J. Trump in 2017, political scandal pervades media coverage on a daily basis. Yet, even the 2016 US presidential election already appeared as juxtaposition of scandalous escapades. Amid a political climate of

\footnotetext{
Corresponding author:

Anna Zeitler, Friedrich-Alexander University Erlangen-Nurnberg, Bismarckstrabe I, 91054 Erlangen,

Germany.

Email: anna.zeitler@fau.de
} 
polarization and citizens' distrust in the national government, coverage of scandals involving both presidential candidates flourished, mediagenicity and entertainment factor often receiving more attention than political proficiency. In 2015, the incumbent president Barack Obama was alarmed by controversial statements of presidential candidate and former reality TV star Donald Trump and his success during the primaries and expressed his concerns during a press conference:

I just want to emphasize the degree of which we are in serious times, and this is a really serious job. This is not entertainment. This is not a reality show. This is a contest for the presidency of the United States. (Manchester, 2016)

A warning that was not heeded: seeking the attention of voters through traditional media channels such as national newspapers and TV channels as well as through social media in order to publicly criticize and defame the opposing team, both the Republican and the Democratic nominee ran their 2016 campaigns with a rough and aggressive tone, focusing on personal attacks to an unprecedented extent. Donald J. Trump's and Hillary Clinton's strategies relied heavily on so-called negative campaigning and media-effective defamation of their opponent as each sought to depict the other as morally unfit for the presidency of the United States. Accordingly, in 2016, scandalizations dominated the 24/7 news cycle; newspapers such as the Washington Post and the New York Times regularly revealed new evidence of both candidates' misconduct, while both campaigns sought to bring up fresh charges almost daily.

From a socio-critical perspective, this scandal overload might be interpreted as a result of relentless moral degeneration or as a sign of a post-truth society - but this reductionist view falls short of understanding the underlying logics of scandal construction. Refraining from normative perspectives that lament the declining quality of political media coverage in the first place, we will focus on the question how discourses of scandal were constructed and evolved in mass media coverage and in the simultaneous discussion on social media in the 2016 US presidential election. In this context, we show how scandal discourses were used by campaigns and candidates as a strategy to redirect both journalists' and the public's attention to their opponent(s).

Re-examining some pertinent theoretical approaches to scandal from the fields of media studies and political science, we want to establish four categories suitable for an analysis of contemporary political media scandal considering the mechanisms and interactions of mass media coverage and social media discourses. Our subsequent analysis aims to exemplify these respective mechanisms by observing two of the most influential scandals of the 2016 election, emailgate and trumptape(s) that we consider to be two interconnected yet heterogeneous phenomena. To show the impact and dynamics of political scandal in a hybrid media landscape, we will demonstrate how the narratives of both emailgate and trumptape emerged and evolved and how they were perceived by the public. Finally, both examples allow us to draw conclusions about newly emerging media convergences by showing how a specific narrative is told, re-told, and modified throughout different media types, and how scandals may rapidly and unexpectedly change direction through their negotiation on social media. 


\section{Political scandals - basic elements and extended impact}

(Political) scandals unfold on different levels of awareness: they generate a certain form of explosiveness, affect different public spheres, and evoke various forms of (public) visibility. Accordingly, scandals are bound to active media involvement. But what does this mean exactly? To understand the constitutive quality of scandals being made and staged in and by media, some of these findings first require re-examination and additional extensions to develop analytical categories.

\section{Emergence}

Although a sudden 'shock-like' outbreak of scandals and their interruptive character are an integral part of their negotiation through media, scandals do not 'just happen'. They need to be incorporated into a certain interpretational framework and discursive negotiation; otherwise, a potential scandal remains nothing but a single incident. Scandals require a narrative that builds on preceding actions which are consecutively framed as having been intentional. While for the initial emergence of a scandal, it does not matter if these actions have really taken place, whether they have been deliberately committed, or if they have just taken place allegedly, scandal can only develop if a person's actions are suitable to be consecutively framed as moral, legal, or ethical transgression of public interest (cf. Dewberry, 2015: 4; Hondrich, 2002: 15). Especially in terms of political scandal, such transgressions must be framed as being of overall public relevance (cf. Thompson, 2000: 18) - if only because any private activity may run counter to the high standards and expectations commonly placed on elected representatives. That being said, it is clear that the transgressions that scandals are built on, especially political ones, 'must be traceable to real persons who are held responsible for their actions', as Lull and Hinerman explain in their study of media scandals. Since it involves an act that is regarded as misconduct and/or morally inappropriate behavior in the broadest sense, every scandal is a deeply personalized affair (Lull and Hinerman, 1997: 4). Accordingly, the emergence of scandals, just like their consecutive narrative development, involves a set of different actors (hereafter referred to as 'participants') that can be observed, evaluated, and judged based on their respective involvement and actions.

\section{Participants}

Scandals necessarily include one (or several) $\operatorname{victim}(s)$ and one (or several) perpetrator(s), most likely figures of public interest. Although in most cases, the specific victim-perpetrator dynamic proves to be considerably more diverse and rather complex, this original binary is an essential prerequisite: as Dewberry highlights, if there is no such thing as an agitator of indignation - or nobody feeling indignant - transgressions may go unheard and unseen (cf. 2015: 4). This also means that the moral dimension of a scandal's initial personalization process, involving a narrative distinction between good and evil, is closely linked to an affective involvement of the audience. To develop into an ongoing public story, transgressions must be framed in a way that allows for (collective) emotional reactions; they must be experienced as serious or at least interesting enough to attract a sustained 
engagement of the audience. If those involved in moral transgressions are already known to the public, they attract the audience's interest almost immediately, and a media scandal is much more likely to unfold. Moreover, scandal communication may become self-referential: 'Where scandals are concerned, a further scandal can be caused by the way a scandal is commented on' (Luhmann, 1996: 29). ${ }^{1}$ Therefore, political scandal has become one of the most common forms of political reporting - especially because politicians, more than other prominent persons, are generally expected to behave morally appropriate both in private and public while paradoxically their lapses are readily anticipated.

While the victim/perpetrator binary is crucial for the narrative of the scandal, people who 'unveil' the truth are equally important participants to make a scandal visible for the public. Traditionally, with regard to political scandal in the United States, this part has been played by professional journalists and mass media acting as watchdogs of democracy. A scandal narrative requires extensive visibility to gain and retain broad public attention. In the United States, what matters most is televised coverage: 'If the story does not appear prominently and repeatedly on TV $[\ldots]$ it matters little to politics or public opinion' (Entman, 2012: 67). While a primary transgression and its publicly mediated disclosure may be the crucial starting point of an outbreak of any scandal, an ongoing media narrative that ensures constant visibility and attention of the public is required for a scandal to fully develop over time. In this sense, many scandal narratives are also entertaining: they attract attention and stimulate an ongoing interest of the audience to see the outcome. In the process, the narrative often changes direction from the initial lapse to a second-order transgression, whereby the original trigger of a scandal may lose its relevance and new aspects or cover-up attempts come into public focus (cf. Thompson, 2000: 17).

\section{Substance}

The individual topics that constitute a scandal can be as diverse as the social fields in which they emerge, but certain topics have proven to be prevalent in scandal coverage in the past. According to Dewberry (2015), '[t]he basis for scandals can be virtually anything, but scandals typically arise from issues related to sex, money, and power' (p. 8). Notably, this holds true for almost all political scandals with a person-centered narrative since sexual misconduct, the misappropriation of money and the misuse of power are generally rated as most serious transgressions of a legal, ethical, moral, or public standards (cf. Dewberry, 2015: 4). Political representatives are likely to be measured by extremely high standards that are not only applied to their public presence but to their private lives as well. In the face of a fast-paced media landscape in which journalists constantly search for new stories, a climate of growing public distrust and personalized attacks by political opponents, even a relatively small transgressions may evolve into a severe scandal if they are both framed and experienced as disruptions, for example, of the public order. However, to define which kind of conduct may be regarded as a serious transgression is not subject to the media alone. It is equally the result of a collective (and often implicit) process of reiteration and social negotiation. Thus, while the logics of mass media coverage that constitute scandalizations may be durable and operate transnationally, the conditions under which a particular transgression may evolve into a scandal are highly contingent, subject to social changes and culturally specific. Again, this holds 
true especially for political scandal as it is most often related to national issues and beliefs. While the global media system may facilitate international visibility of scandals that are already in full progress, it depends on the respective moral, norms, and values of a particular national political culture which transgressions are serious enough to be framed and perceived as scandal in the first place (cf. Thompson, 2000: 116). Yet, even within one and the same political culture, many different, sometimes competing, moral beliefs and values prevail and are constantly renegotiated which makes it impossible even for advanced journalists and political experts to predict how and if a scandal will ignite and how it will be evaluated by the public.

\section{Perception}

As indicated above, scandals are necessarily bound to attention and visibility - both provided by and through mass media. If they do not receive sufficient mass media attention, scandals will not be perceived by the broad public, which automatically means that they will not fully emerge at all:

Scandal also involves (a) a degree of public knowledge of the actions or events, (b) a public of non-participants who knew about them, and (c) a process of making public or making visible through which the actions or events become known by others. (Thompson, 2000: 19)

This process is always a mediated process; therefore, scandal can also be understood as a media event. In their influential definition of media events, Couldry and Hepp describe them as 'certain situated, thickened, centering performances of mediated communication that are focused on a specific thematic core, cross different media products and reach a wide and diverse multiplicity of audiences and participants' (Couldry et al., 2010: 12). This definition can easily be applied to scandals, particularly with regard to the aspect of visibility. Visibility does not only mean to show certain things but also to hide others, and it is thus inextricably linked with media on two levels. First, on the level of media's immanent functional logic: media make things (events, stories, etc.) visible - show them - and therefore perceptible, while they elude visibility - hide - by retreating behind the content that they show. This way, media maintain the illusion of direct, smooth, and immediate perception. Second, on the level of content: the crucial processes and strategies of media in which things are made visible or remain invisible are highly selective - some things are reported, others are not, some aspects are highlighted, others are dropped, followed by the principle of an 'economy of attention'. On one hand, this principle is a necessary condition and neutral prerequisite for every kind of media event. On the other hand, it is precisely why media events are often perceived as staged, constructed, and factitious, and why media reporting is always criticized for being manipulative or being involved in a cover-up scandal.

From a constructivist viewpoint mass media represent rather than critically inform the public. From a systems-theoretical viewpoint, the public serves as a medium for social systems such as law and politics to observe their environment as well as themselves (Luhmann, 1996: 103ff.). In the case of politics, this leads to a stable interdependency of politics and mass media. Politicians' self-observations are mirrored in media 
coverage, but most often they interpret media reporting as an expression of opinions of the electorate. This has far-reaching consequences, not only for political communications in elections but, concomitantly, for the emergence of media scandals. Since media do have a preference for scandal, political communication increasingly focuses on moral issues and individual persons. Especially in election campaigns, politicians now can only come to power if they constantly remain publicly visible. Thus, they have to stage themselves for a $24 / 7$ media audience of potential voters. To attract media attention and receive coverage by pointing to an opponent's (alleged) transgression can be an effective way of negative campaigning. If a scandal ignites, it can have tremendous consequences on the mediated representation of public opinion over a longer period and thus influence audiences' emotions and opinions regarding the perpetrator(s). When a politician is publicly perceived to be morally unfit for the office, he or she runs for due to the media's scandal narrative, the opponent may often appear as better choice. However, as the analysis of examples from the 2016 US presidential election is going to show, this sort of campaign strategy entails a high degree of contingency. Moreover, if two already unpopular candidates run for office, a media focus on moral failures of persons and scandals may encourage the campaigns to focus even more on candidates' public as well as private personality rather than political issues in order to receive media coverage and remain visible. Candidates may try to draw the attention to any sort of private transgression of their opponent to damage his or her public image. As we shall see, this may even result in an overall public perception that both candidates are ineligible.

\section{Political scandals and new media}

Today, due to new modes of interactivity as well as multi-optional or multi-modal forms of reception and production, we do not only deal with an unprecedented level of media visibility but are also confronted with an undeniable increase of speed of information exchange. Whereas the power of unleashing a scandal may in principle be shifting from professionals to practically everyone, it would be a mistake to assume that a scandal can fully evolve without mass media coverage (cf. Detel and Poerksen, 2012: 13, 33). Albeit new visual and narrative possibilities of social network communication that may easily raise susceptibility to scandals and lead to their viral dissemination in partial public spheres, mass media coverage is still vital to establish a coherent scandal narrative that reaches a broad public. Scandalizations might be even more ubiquitous today as prominent political figures are relentlessly observed and judged not only by mass media but also by digital media publics. The discursive negotiation of scandals is thus no longer limited to television or newspapers but can unfold additionally and simultaneously in diversified social media channels and platforms that offer 'digital public spaces' for highly emotionalized public discourses, moralized discussion, and evaluation of candidates. If negotiated in social media channels, the 'spiral of outrage' can spin faster than ever: 'everybody' may in principle participate not only in monitoring but also in co-creating a scandal by influencing the narrative. Therefore, the interrelationship of new media and traditional mass media can mutually reinforce scandalization due to the communicative logic of convergence culture. Memes or tweets that are used to comment on a scandal on Twitter, for instance, may be reintegrated in classic TV news as they can 
serve as templates for unexpected narrative twists. Spreading, disseminating, and resuming scandals within the shortest possible time frame has never been easier.

\section{Analysis}

\section{\#Emailgate}

On 12 November 2016, 4 days after Donald J. Trump unexpectedly won the Presidential election, the Washington Post reported that Hillary Clinton explicitly blamed Federal Bureau of Investigation (FBI) director James B. Comey for her loss, accusing him of having raised doubts about her trustworthiness by reopening closed investigations in the so-called 'email-affair', also known as emailgate, 11 days before Election Day (Gearan, 2016). Clinton's reaction emphasizes the growing importance of mediated scandal narratives for the public image of political figures. In retrospect, this becomes clear when we consider the discursive negotiation to the emailgate scandal.

Emergence. The events that ignited the email affair date back to Hillary Clinton's term as secretary of state in 2009 but did not become an issue of public debate until the New York Times dedicated a front-page article to the subject on 2 March 2015 (Schmidt, 2016). According to the New York Times, a house committee had discovered that Clinton had used a private email account for government business in the course of investigations of the attack on the American consulate in Benghazi that took place during Clinton's term. Hillary Clinton was not the only US government official who had used a private account for some business mails, but her exclusive use not only of a private account but also a private server attracted the investigators' attention. The state department marked the case as problematic for several reasons, highlighting that Clinton's transgressions happened during her term as secretary of state and thus were considered to be of public relevance: First, the exclusive use of a private email address and server was rated as a violation of security standards for confidential government material, increasing the risk of top secret information falling into the wrong hands in case the account was hacked. Second, the investigators discussed whether Clinton's practice involved a violation of the law, since regulations required any emails sent or received from personal accounts to be archived as part of the agency's records. Finally, the case was accompanied by an air of secrecy and lack of transparency that both Hillary and Bill Clinton had been criticized for in the past, dating back to the scandals of Bill Clinton's presidency. All three initial charges contributed to the general notion that the Clintons - as public representatives - had deliberately used their private server to withhold and control information of public relevance. As the FBI investigation focused on whether Hillary Clinton could be held legally responsible, the case provided ideal conditions to be framed as a political scandal in the first place. Whether the potential violations of law and security were intentional remained unclear, but since Clinton's actions were considered to be 'extremely careless behavior' by the investigators, her opponents and the media, the story caused public outrage.

Participants. When the first accusations against Hillary Clinton were made public, she was initially considered as the main perpetrator. As a high-ranking politician, Clinton 
held an office which required her to be trustworthy. Journalists and political adversaries referred to controversial moments of her past political career in order to frame her actions as intentional wrongdoings at the expense of public safety. Both their political prominence and previous media narratives about the Clintons played a crucial role in the framing of the email controversy and lead to sustained public interest. After a number of scandals and unsuccessful cover-ups that the Clintons had been involved with in the past (i.e. Flowers, Lewinsky, Whitewater, and Benghazi), the use of a private server made Hillary Clinton look even more suspicious and morally questionable. The notion of secrecy became especially troubling when FBI investigations revealed that Clinton had instructed her team to destroy several mobile devices, and that she had not handed in all relevant emails after having vowed to do so, persisting that some of those emails were entirely private and not intended for the general public. Accordingly, as the scandal narrative evolved, media coverage focused less on the initial transgressions and more on Clinton's attempt to cover-up her alleged wrongdoings. After the case was closed in July 2016, the FBI exonerated Clinton from any violations of the law. However, FBI chef Comey resumed the case in late October, only 11 days before Election Day since new emails that were relevant to the case were found on a computer shared by former congressman Anthony Weiner and Huma Abedin, Clinton's employee. Like Bill Clinton, Weiner himself had been involved in various sex scandals in the past. In this context, the narrative of Bill Clinton's former sex affair scandal was rolled out anew. Conjuring up memories of Bill's perjury, the name 'Clinton' was once again considered as a synonym for dishonesty and put under general suspicion. With this 'October surprise' - as critical revelations about a presidential candidate shortly before Election Day are commonly called - the emailgate narrative developed into two competing directions. As FBI chef and former republican James Comey re-opened the case close to Election Day but did not specify why the content of the emails found Weiner's and Abdin's computer justified new investigations at this particularly critical time of the electoral cycle, Clinton supporters experienced Comey's actions as a manipulation of the election and thus a political scandal of its own. Clinton adversaries on the other hand experienced the new charges as an extension of the previous scandals and a confirmation of the Clintons' wrongdoings. Hillary's lapses were almost negotiated as if they were the expectable and unavoidable sequel story of her husband's rise and fall: Her former role as first lady and secretary of state made Hillary Clinton particularly vulnerable as a public political figure. The high moral standards and expectations placed on elected representatives that contributed to the framing of the emailgate scandal reveal the conflicting expectations of the public regarding politicians' negotiation of their private and public affairs: When Clinton tried to preserve her right to hold private conversations, she was accused of restraining material of public interest. Moreover, the fact that she had not followed her advisor's suggestions to separate private emails from business conversations out of convenience let her actions come across as particularly careless. This contributed to the impression that Clinton had broken the rules intentionally and in full awareness, and then had reacted in an inappropriate way when she was 'caught'.

Substance. While the content of the emails and possible violations of law were of interest when the emailgate scandal originally emerged, quite rapidly, media discourse rather 
focused on superordinate questions of trust, truth, and integrity. Hillary's damaged credibility became the dominating narrative while the attempted acts of cover-up contributed to this image. Mass media framed the case as obscure in the beginning, and Donald J. Trump used it to build his own narrative of crooked Hillary, branding her as a criminal by recurrently using the term in his tweets, further fueling public indignation (cf. Itkowitz, 2016). Accordingly, infuriated Twitter users repeatedly employed the hashtag 'crookedHillary' in the final weeks of the 2016 electoral cycle to refer to new developments in the email affair and former scandals of the Clintons. Trump also constantly referred to 'crooked Hillary' at his rallies, a narrative that was picked up by the mass media again who observed both the candidates' public speeches and their social media accounts on a daily basis. Although it remained unclear throughout the FBI investigation whether Hillary Clinton had really violated the law, the mass media, representing public opinion, automatically raised further suspicion by giving attention to her opponents' accusations. When the case was re-opened by the FBI, Trump called it 'the biggest thing since watergate', putting emailgate in line with what the public memorized as of one of the first and most famous modern mediated political scandals in US history. This strategical framing resulted in the evocation of collectively shared memories. Once again, it illustrates the extent to which processes of scandalization as a media event are susceptible to and dependent on contextualization and embedding in the 'big picture'.

Politicians like the Clintons are expected to behave 'morally appropriate' both in private and as public figures while paradoxically their lapses are readily anticipated, since expecting the unexpected is essential for media coverage, media events (and thus for scandals), and politics. In the case of emailgate, the result was a constant and eager incorporation of every little rumor into the extensive, well-kept, and highly visible narrative of 'crooked Hillary'.

Perception. Crooked Hillary and emailgate were successfully kept alive, in particular due to the Trump campaigns' best efforts. Mass media rapidly focused on the issue in their $24 / 7$ news coverage and pushed ongoing speculations. New developments of the case as well as secondary scandals such as the hack of the Democratic National Committee (DNC) email system and all kinds of (seemingly) delicate details were carefully woven into the narrative, following an economy of attention. The serial narrative could fruitfully develop, especially since all actors involved had already been part of former scandalizations that stuck to the public memory. These stories were quickly revived in the course of new developments. Although no incriminating content was found in the emails, all cover-up attempts of the Clinton campaign and the discrepancy between Hillary Clinton's private and public image contributed to a general feeling of public distrust that was intensified by her opponents' social media statements. Outrage and indignation could flourish particularly well on Twitter and Facebook as public feelings were heated up by the Trump campaign, promising to 'lock her up' and became topics of mass media coverage on the scandal since they were observed as expressions of public opinion. While other topics pertaining to the election were put aside, the email affair and its newest developments developed into an all-encompassing media event, since the mass media referred to and re-actualized past events to explain, contextualize, or frame the current event. By doing so, they reinvigorated discourses that pervaded the US society's 
collective memory. The email scandal remained an issue of public interest and media coverage throughout the entire electoral cycle. Clinton supporters perceived the ongoing charges and media reporting as a campaign of lies incited by the Trump team. Trump supporters, on the contrary, criticized the mass media for not being biased and critical enough, reporting in favor of Hillary Clinton, especially after leading national newspapers officially endorsed her. Some Republicans reproached the 'liberal media' of trying to protect Clinton by performing part of the cover-up of the scandal.

Even within a climate of extreme political polarization and broad distrust in media on both sides of the political spectrum, mediated representations of public opinion are still a critical factor in deciding whether a candidate will be perceived as fit for office. But while it is now possible for political campaigns to spin mass media coverage in favor of one candidate and against the opponent more easily if they manage to manipulate social media discourses, the success of such strategies remains highly contingent. As the upcoming example of the trumptapes will reveal, one of the reasons why the trumptapes scandal turned out to have less serious consequences for the candidate than the email affair had for Clinton is a consequence of the logics of mass media coverage and public media distrust.

\section{\#Trumptape(s)}

On 7 October 2016, 2 days before the second US presidential debate 2016, the online editorial team of the Washington Post published an article entitled 'Trump recorded having extremely lewd conversation about women in 2005 ' written by David A. Fahrenthold. The text was accompanied by a video of a private conversation between Donald J. Trump and Billy Bush of 'Access Hollywood'. The video that had been recorded in 2005 did not show images of Trump and Bush talking, but their voices could be clearly identified. In the recording, Trump bragged about his sexual advances toward women that he had been attracted to in the past using vulgar and degrading vocabulary and invoking his celebrity status as carte blanche for sexual assault: 'And when you're a star, they let you do it. You can do anything. [ ... ] Grab them by the pussy' (Fahrenthold, 2016). While the recording provided sufficient evidence to confront Trump with his statements and moreover drove the attention to further instances in which Trump had insulted women in the 2016 election cycle, public outrage initially led to a highly emotional public debate as well as demands that Trump should withdraw his candidacy. However, unlike the emailgate that became the Achilles heel of the Clinton candidacy, the trumptape(s) scandal did not have significant long-term implications for Trump's campaign. This seems remarkable, especially since the video recording, in contrast to the contents of emailgate that were mostly inaccessible to the public, provided a digital piece of media evidence that made Trump's morally inappropriate sexist statements available to everyone with Internet access. Typically, the glorification of sexual harassment disqualifies a politician for any public position, and especially for the presidency of the United States, considering the high moral and ethical standards that US presidents as leaders of the nation are generally measured by. As the first 2 years of Trump's governance have been surrounded by daily scandal, the question why neither the trumptape controversy nor any of the subsequent scandals terminated his campaign or ensuing presidency has become even more pressing. 
Emergence. In contrast to the emailgate scandal that protracted over a long time even before the election, the timing of the initial trumptape release happened at the peak of the 2016 campaign season. While the outbreak of the trumptape(s) scandal might have been experienced as abrupt when the respective Washington Post article was published, the video recording was not an overnight discovery but was not released until a crucial point of time in the electoral cycle had been reached. In the wake of offensive comments against former beauty queen Alicia Machado, a producer of National Broadcasting Company $(\mathrm{NBC})$ had remembered that the tape was still stored in the archive of the channel and while the producing team debated about its release for several days, an unknown source leaked the recording to David Fahrenthold from the Washington Post. Fahrenthold immediately published his story together with the video only 2 days before the second presidential debate, thus ensuring maximum public visibility. While the story would have been certainly disadvantageous at any moment of the election, it was also discussed in the presidential debate and thus exposed to the national and international public. Trump's former verbal offenses against different prominent women provided the interpretative framework for a continuous line of his sexist statements and moral transgressions into which the old tape was incorporated and thus reframed to become subject of present public discourse. To many observers, this well-timed emergence of the trumptape scandal appeared to be part of the game plan. The impression of bias was reinforced by the leading media's former decision to endorse Hillary Clinton, contributing to the everpresent public distrust in mass media objectivity, especially among Trump supporters.

Participants. The media framing of victim(s)-perpetrator dynamics in the trumptape(s) scandal clearly foregrounded Donald J. Trump's moral transgressions while Billy Bush of NBC was incidentally treated as secondary perpetrator. While the main focus was on Trump and the question whether his utterances disqualified him for the presidency, Trump was publicly criticized but not convicted. Instead, NBC terminated Billy Bush's contract. For Trump and his campaign, however, the tape did not even have serious legal consequences when the producers of The Apprentice promised to publish additional tapes that contained sexist Trump statements, and when several victims of Trump's alleged sexual harassments publicly spoke about their experiences. Nevertheless, these developments caused considerable public outrage. While social media discourse was dominated by trumptape and later trumptapes hashtags for a couple of days, many US politicians, both Democrats and Republicans, publicly disapproved Trump's statements. Most of them demanded that Trump should resign, but Trump continuously refused to do so. The story also occupied all newspapers and TV channels, bearing a potential explosiveness especially since it emerged just 2 days before the second presidential debate and became a major talking point of the debate. However, while Hillary Clinton had been publicly judged by the moral standards applied to an established politician in the email affair, Trump's behavior was not measured by political standards. Instead, he was still considered as a businessman and reality TV celebrity even in the final days of his campaign. Although Trump's offensive statements about women earlier in the election cycle and other scandals during his career were used to feed the media narrative, his celebrity status did not subject Trump to the same public expectations of moral and legal integrity that Hillary Clinton had been measured by. As a former reality TV host, Trump had continuously uttered morally 
questionable and extreme statements with high entertainment value corresponding to the conventions of the program. As Lorenz Engell has pointed out, celebrities that are a product of television are oftentimes not harmed by scandal and may also profit from it, as they are highly dependent on continuous public visibility (cf. Engell, 2005: 29). In fact, repeated breaks with political correctness were the core part of Trump's successful construction of his public persona as counter-image to allegedly corrupt political elites throughout his 2016 campaign. This sort of staged authenticity may best be summarized by Trump's own words: 'I say it, as it is'. Moreover, although his statements where harshly criticized by the mass media, the logic of the media as political watchdogs that contributed to the downfall of Hillary Clinton did not equally apply to the case of the trumptapes scandal. As the scandal was ignited at a time when leading mass media had already given Hillary Clinton an endorsement and were no longer considered to be 'objective', Trump continuously staged himself as victim of the 'liberal media' and described the scandal narrative as 'fake news' which his supporters readily believed. For Trump, this sort of media blaming has now become a successful strategy of self-defense that he has incorporated into his presidential communication techniques and that he has used repeatedly to downplay various scandals. With the trumptape being released by the Washington Post 2 days before the second debate, for many Republicans the scandal came across as joint conspiracy of the mass media and the Clinton campaign and thus as an insolent manipulation of public opinion. Moreover, despite several allegations, no legally valid evidence was found that Trump had really committed any sexual misconduct. In addition, Trump immediately apologized to the public for his inappropriate words and concurrently downplayed the importance of the tape by referring to his conversation as common 'locker-room talk', a conversation of casual sexism among men in private.

Substance. The trumptape(s) scandal clearly lacked substance, so the media narrative could not develop into a long story and did not entail political consequences. In contrast to the emailgate scandal that evidently involved false statements of a political figure as well as unsuccessful cover-up attempts and a threat to public safety, the trumpstape(s) case entailed no denial, no proof for further misconduct, and consequently no cover-up attempt. The morning after the tape was leaked, Trump issued a videotaped apology stating that he was not a perfect person and that the tape did not reflect who he was. In the video, he conceded, 'I've said and done things I regret, and the words released today on this more than a decade-old video are one of them'. ${ }^{2}$ Moreover, in the closing statement, he referred to Bill Clinton's former sex scandals which not only evoked the public memory of the former president's sexual misconduct but also made Hillary Clinton, who had expressed her disgust about Trump's words, look like a hypocrite since she had defended her husband's actions in the past. By declaring that 'there's a big difference between $[\ldots]$ words and actions', Trump relativized his own statements and, at the same time, drew the attention back to the Clinton scandals. Moreover, as Trump had publicly pronounced various sexist insults against women during his campaign that had caused outrage before, the tape did not really reveal anything new or unexpected about his character. In contrast to the emailgate narrative that developed in the field of tension between private and public, Trump staged himself as the same person in private and in public; a reality TV host and Washington outsider speaking out against political correctness. His public apology 
was only the first measure to lead the public attention away from himself by directing it back to the Clinton scandals. Only hours before the second presidential debate, Trump spontaneously announced that he was going to host a press conference that would be live-streamed on Facebook. In this conference, he presented four women who had formerly prominently sued Bill Clinton for rape, and now defended Trump while attacking Hillary Clinton for having threatened them back in her days as a lawyer. By bypassing cable TV and staging his private (social) media event, Trump was free to set the narrative of the broadcast, but at the same time captured the attention of the mass media who subsequently reported on the event. Consequently, newspapers and television reporting brought the Clinton sex scandal back into the overall public perception again just at the moment of the second presidential debate while trumptape(s) slowly faded out of view.

Perception. A crucial difference of the trumptape(s) scandal and the narrative of emailgate lies in the public perception of both the transgressions and the victim/perpetrator dynamics. While emailgate involved clear evidence, unsuccessful cover-ups and detectable lies, the trumptape(s) clearly lacked evidence for a transgression that went beyond inappropriate language. Trump supporters accused the women who testified that they had been victims of Trump's sexual advances of having been hired by the Democrats to damage his campaign; Similarly, they considered the outrage on mass media as an attempt to manipulate public opinion in favor of Clinton. Thus, many citizens felt that the media had failed to fulfill their role as objective watchdogs of democracy and that they misused their power to damage the image of Donald Trump.

Although trumptape(s) was highly visible at the beginning, thanks to the leaked video, public attention quickly shifted back to the Clintons and Bill Clinton's former actions of sexual misconduct, contributing to the notion that the scandal was a product of Trump's adversaries. In turn, this development gave Trump the possibility to stage himself as a victim of leading US newspapers (?), claiming that the election was rigged, thereby contesting the legitimacy of a possible Clinton victory from the outset. Moreover, although especially women denounced Trump's sexist language on Twitter under the hashtag \#lockerroomtalk, Trump was also defended on social media by a large number of men who did not consider the tape a moral transgression in the first place. Instead, they stated that this was simply the way men talked about women in private and prompted the public to calm down. This sort of defense consolidated Trump's staging of himself as the same person in public and in private and served to downplay his sexist language that had been appealing to many of his supporters before. As a well-known former reality TV star with no preceding political career, Trump was able to reinterpret the media narrative of the scandal in favor of his public image as outsider. For those who supported him from the beginning, the scandal appeared as a joint conspiracy of the hated Washington elite and liberal media.

\section{Conclusion}

The analysis and comparison of the emailgate and trumptape(s) scandals has illustrated that the effects and developments of mediated processes of scandalization are highly contingent and subject to collective negotiations. In the case of the Clinton email scandal, 
Hillary was judged by the moral expectations toward a political figure and comparatively high standards. Moreover, her public image was damaged by a scandal-ridden history of former transgressions associated with her office and her husband. Unsuccessful cover-up attempts as well as an attempt to differentiate her private from her public persona led to an increase of public distrust that was additionally fueled by a constant media coverage on new charges against her. The trumptape(s) scandal was a different matter altogether. As a reality TV celebrity, Trump did not face the same moral expectations that established politicians are subjected to and, therefore, the scandal could barely do serious damage to his public image. Instead, he profited from media visibility and coverage, which he partly generated himself by attracting attention through Twitter statements that were constructed to entertain and appall, tailored to the mass media's preferences. Due to a lack of evidence of sexual misconduct as well as his constant claims that the media were biased against him, Trump's followers did not experience his moral transgressions as serious enough for the scandal to maintain the same kind of longevity as the emailgate affair that was later considered as key factor in Hillary Clinton's election loss. His supporters rather saw him as a victim of media manipulation and of a smear campaign instigated by the Democrats. The liberal narrative that criticized Trump's sexism did not develop into an all-encompassing joint public outrage since a large part of citizen did not consider his statements as morally wrong.

\section{'If the election had been on Oct. 27, I would be your president': the aftermath of trumptapes and emailgate}

Although Trump's various scandals did not get in the way of his election victory, they initiated a public debate about the legitimacy of his presidency in which previous scandals were constantly revisited and re-iterated, while new scandals emerged throughout the first 2 years of his presidency almost on a daily basis. However, Trump has been able to frame himself as victim of the liberal media until the present day and thereby successfully defended his office until so far. Nevertheless, Trump's transgressions gave rise to public protest. In the Women's March on Washington in January 2017, right after Trump's inauguration, references to the trumptapes scandal and Trump's sexist statements were ubiquitous not only in speeches and on protest signs but also in the form of the so-called 'pussyhats', handmade pink cat eared knit hats produced and distributed by a grassroots project as a reminder of Trump's inappropriate 'grab them by the pussy' statement and as a warning to prevent this type of sexism from becoming socially accepted.

While Trump appears to be immune to any serious legal consequences despite his daily lapses, the email affair clearly developed to the detriment of Hillary Clinton's presidential campaign. Therefore, Hillary Clinton held the head of the FBI, James Comey, accountable for her loss and claimed that the FBI reinvestigation of the email affair in the final 10 days before Election Day had caused her defeat. Thus, Clinton portrayed herself as a victim of the FBI's questionable timing. In her critique, Clinton did not refer to the impact of negative social media discourses that had played an important part in disseminating and reinforcing the suspicions and accusations against her. 


\section{Forecast: the future of mediated scandal}

With regard to the growing importance of social media as platforms of public debate and loci of political discourse, the digital realm is likely to develop into a battlefield in the fight for sovereignty over scandal discourse, political attitudes, and thus negotiation of social norms, morals, and values - a partial public sphere that continuously attracts the attention of the mass media seeking for new and entertaining stories. Both the reciprocity of media coverage and political norm violations and the growing polarization of the political landscape in the US might either lead to a further increase in moral conflict in form of scandals or to a decline in scandalization. Regarding media coverage of the Trump presidency in the past 2 years, the latter appears to hold true, since Trump's logic of provocation - constant deviations and transgressions - have become the new 'normal' in daily political discourse. As the events surrounding the controversial swearing-in of Supreme Court judge Brett Kavanaugh despite suspicions of sexual assault have shown just recently, the criteria for the prosecution of transgressions of political figures seem to have been lowered.

\section{Funding}

Authors were holders of a german research foundation graduate scholarship from 2015-2018.

\section{Notes}

1. According to Luhmann, mass media also create a constant state of awareness of irritation due to their focus on news value (cf. Luhmann, 1996: 47). This means that expecting the unexpected and anticipating an irritation are common modes of perception. Correspondingly, scandals are consequently defined by clear expectations. This may lead to peculiar strategies of scandal construction as in the case of a 'October Surprise' shown later.

2. Available at: http://www.nytimes.com/2016/10/08/us/donald-trump-apology-statement.html (accessed 3 December 2016).

\section{ORCID iD}

Anna Zeitler (iD) https://orcid.org/0000-0003-0415-6291

\section{References}

Couldry N, Hepp A and Krotz F (2010) Media Events in a Global Age. New York: Routledge.

Detel H and Poerksen B (2012) The Unleashed Scandal: The End of Control in the Digital Age. Exeter: Imprint Academic.

Dewberry DR (2015) The American Political Scandal: Free Speech, Public Discourse, and Democracy. London: Rowman \& Littlefield.

Engell L (2005) Fall und Fälle: Kleine Philosophie des Fernsehskandals. In: Borg S, Gerhards C and Lambert B (eds) TV-Skandale. Konstanz: UVK, pp. 18-37.

Entman R (2012) Scandal and Silence: Media Responses to Presidential Misconduct. Cambridge: Polity Press.

Fahrenthold DA (2016) Trump recorded having extremely lewd conversation about women in 2005. The Washington Post. Available at: https://www.washingtonpost. com/politics/trump-recorded-having-extremely-lewd-conversation-about-women-in2005/2016/10/07/3b9ce776-8cb4-11e6-bf8a-3d26847eeed4_story.html?utm_term=.cbefc6c5b2f8 (accessed 02 December 2016). 
Gearan A (2016) Hillary Clinton blames one Comey letter for stopping momentum and the other for turning out Trump voters. The Washington Post. Available at: https://www.washingtonpost. com/news/post-politics/wp/2016/11/12/hillary-clinton-blames-one-comey-letter-for-stoppingmomentum-and-the-other-for-turning-out-trump-voters/ (accessed 22 November 2016).

Hondrich KO (2002) Enthüllung und Entrüstung: Eine Phänomenologie des politischen Skandals. Frankfurt am Main: Suhrkamp.

Itkowitz C (2016) 'Little Marco', 'Lyin' Ted', 'Crooked Hillary': how Donald Trump makes name calling stick. The Washington Post. Available at: https://www.washingtonpost.com/news/ inspired-life/wp/2016/04/20/little-marco-lying-ted-crooked-hillary-donald-trumps-winningstrategy-nouns/?utm_term=.256afaf8760f (accessed 02 December 2016).

Luhmann N (1996) The Reality of the Mass Media. Stanford, CA: Stanford University Press.

Lull J and Hinerman S (1997) Media Scandals: Morality and Desire in the Popular Culture Marketplace. New York: Columbia University Press.

Manchester J (2016) Obama on election: 'this is not entertainment'. CNN Politics. Available at: http://edition.cnn.com/2016/05/06/politics/barack-obama-donald-trump-election/ (accessed 22 November 2016).

Schmidt MS (2016) Hillary Clinton used personal email account at state dept., possibly breaking rules. The New York Times. Available at: http:/www.nytimes.com/2015/03/03/us/politics/ hillary-clintons-use-of-private-email-at-state-department-raises-flags.html?_r=1 (accessed 22. November 2016).

Thompson JB (2000) Political Scandal: Power and Visibility in the Media Age. Cambridge: Polity Press. 